\title{
Analysis of the Polyphenols of Tobacco Using Pressurized Liquid Extraction (PLE) and Ultra Performance Liquid Chromatography With Electrospray Ionization - Tandem Mass Spectometric Detection (UPLC-ESI-MS/MS) *
}

\author{
by \\ John R. Shifflett, Leah Watson, Devin J. McNally, and Dawit Z. Bezabeh \\ United States Department of the Treasury, Alcohol and Tobacco Tax and Trade Bureau (TTB), Beltsville, MD, USA
}

\section{SUMMARY}

Polyphenols are chemicals found in tobacco that are affected by the method used to cure the leaf and, as a result, can be useful in the characterization of tobacco products. The purpose of this work was to develop an analytical method to investigate the levels of six polyphenols found in tobacco leaves and tobacco products: 3-O-caffeoylquinic acid (chlorogenic acid), 4- $O$-caffeoylquinic acid (cryptochlorogenic acid), 5-O-caffeoylquinic acid (neochlorogenic acid), kaempferol 3-O-rutinoside (nicotiflorin), quercetin 3$O$-rutinoside (rutin), and 6-methoxy-7-hydroxycoumarin (scopoletin). Extraction conditions for sample preparation using PLE and instrument conditions for analysis by UPLC-MS/MS were optimized and validated. Results from the analysis of 30 cured tobacco leaves are presented and discussed in the context of each curing method represented. Results from the analysis of various tobacco products are also presented and trends observed across product types are discussed in the context of the applicability of the validated method. Total polyphenol levels for flue-cured, Oriental, and air-cured leaves were determined to be in the ranges of $18-41 \mathrm{mg} / \mathrm{g}, 5-27 \mathrm{mg} / \mathrm{g}$, and $0.5-3 \mathrm{mg} / \mathrm{g}$ respectively. Similarly, cigarette polyphenol levels were found in the range of $4-16 \mathrm{mg} / \mathrm{g}$ and cigar polyphenol levels were less than $1.5 \mathrm{mg} / \mathrm{g}$. The trends observed in the results for the tobacco leaf samples are consistent with expectations regarding the fate of polyphenols under the conditions commonly used in curing procedures. The results for the tobacco products demonstrate that the validated method can be used to study polyphenol content in cigarettes and a variety of cigar types including pipe tobacco cigars. [Beitr. Tabakforsch. Int. 27 (2017) 195-207]

\section{ZUSAMMENFASSUNG}

Polyphenole sind im Tabak vorkommende Substanzen, die durch die Methode zur Trocknung der Tabakblätter beeinflusst werden und deshalb für die Charakterisierung von Tabakprodukten hilfreich sein können. Ziel der vorliegenden Arbeit war die Entwicklung einer Analysemethode zur Untersuchung der Konzentrationen von sechs Polyphenolen, die in Tabakblättern und Tabakprodukten vorkommen: 3-O-Caffeoylchinasäure (Chlorogensäure), 4-O-Caffeoylchinasäure (Cryptochlorogensäure), 5-O-Caffeoylchinasäure (Neochlorogensäure), Kämpferol-3-O-rutinosid (Nicotiflorin), Quercetin-3-O-rutinosid (Rutin) und 6-Methoxy-7-hydroxycumarin (Scopoletin). Die Extraktionsbedingungen zur Probenvorbereitung mittels PLE sowie die 
Gerätebedingungen für die Analyse mittels UPLC-MS/MS wurden optimiert und validiert. Es werden die Ergebnisse der Analyse von 30 getrockneten Tabakblättern vorgestellt und im Kontext jedes einzelnen Trocknungsverfahrens erörtert. Außerdem werden die Ergebnisse der Analyse verschiedener Tabakprodukte vorgestellt und die beobachteten Trends für alle Produktsorten im Zusammenhang mit der Anwendbarkeit der validierten Methode erörtert. Der ermittelte Gesamtpolyphenolgehalt lag jeweils bei heißluftgetrockneten Blättern (Flue-cured) im Bereich $18-41 \mathrm{mg} / \mathrm{g}$, bei Orienttabak im Bereich 5-27 mg/g und bei luftgetrockneten Blättern (Air-cured) im Bereich von 0,5-3 mg/g. Desgleichen wurde bei Zigaretten ein Polyphenolgehalt im Bereich von 4-16 mg/g festgestellt, während er bei Zigarren unter 1,5 mg/g betrug. Die in den Ergebnissen der Tabakblätterproben beobachteten Trends stimmen mit den Erwartungen bezüglich des Verbleibs von Polyphenolen unter den bei Trocknungsverfahren gewöhnlich zur Anwendung kommenden Bedingungen überein. Die Ergebnisse der Tabakprodukte zeigen, dass die validierte Methode verwendet werden kann, um den Polyphenolgehalt in Zigaretten sowie in diversen Zigarrensorten, einschließlich Zigarren mit Pfeifentabak, zu untersuchen. [Beitr. Tabakforsch. Int. 27 (2017) 195-207]

\section{RESUME}

Présents dans la tabac, les polyphénols sont des substances chimiques affectées par la méthode de séchage de la feuille et ils peuvent, par conséquent, servir à la caractérisation des produits de tabac. La finalité du présent travail fut de mettre au point une méthode analytique en vue de l'étude des niveaux des six polyphénols présents dans les feuilles et les produits de tabac, à savoir l'acide 3-O-caffeoylquinique (acide chlorogénique), l'acide 4- $O$-caffeoylquinique (acide cryptochlorogénique), l'acide 5-O-caffeoylquinique (acide néochlorogénique), le kaempférol 3-O-rutinoside (nicotiflorine), la quercétine 3-O-rutinoside (rutine) et la 6méthoxy-7-hydroxycoumarine (scopolétine.). Les conditions pour la préparation de l'échantillon reposant sur une extraction par liquide sous pression (PLE) et les conditions des équipements pour l'analyse par UPLC-MS/MS (chromatographie en phase liquide ultra performante couplée à une spectrométrie de masse en tandem) furent optimisées et validées. Les résultats de l'analyse de 30 feuilles de tabac séchées furent exposés et débattus selon chaque méthode de séchage incluse dans l'étude. Les résultats de l'analyse des divers produits de tabac furent également exposés et les tendances observées à travers tous les types de produits furent débattues selon l'applicabilité de la méthode validée. Les niveaux totaux de polyphénols pour les feuilles de tabac jaune, de tabac d'orient et de tabac séché à l'air furent mesurés dans des plages allant respectivement de 18 à $41 \mathrm{mg} / \mathrm{g}, 5$ à $27 \mathrm{mg} / \mathrm{g}$ et 0,5 à $3 \mathrm{mg} / \mathrm{g}$. De même, les niveaux de polyphénols présents dans la cigarette furent mesurés dans une plage de 4 à $16 \mathrm{mg} / \mathrm{g}$ et ceux des polyphénols présents dans le cigare furent inférieurs à $1,5 \mathrm{mg} / \mathrm{g}$. Les tendances observées parmi les résultats obtenus pour les échantillons de feuilles de tabac concordent avec nos attentes quant au devenir des polyphénols dans les conditions communément appliquées lors des pro- cessus de séchage. Les résultats pour les produits de tabac attestent que la méthode validée peut servir à l'étude de la teneur en polyphénols des cigarettes et de divers types de cigares, y compris les cigares à base de tabac pour pipe. [Beitr. Tabakforsch. Int. 27 (2017) 195-207]

\begin{tabular}{ll}
\hline Abbreviations & \\
\hline PLE & Pressurized Liquid Extraction \\
UPLC & Ultra Performance Liquid Chromatography \\
MS & Mass Spectrometry \\
ESI-MS/MS & Electrospray lonization - Tandem Mass \\
& Spectrometric Detection \\
TTB & U.S. Alcohol and Tobacco Tax and Trade \\
PPO & Bureau \\
LC-UV & Polyphenol Oxidase \\
LC-MS & Liquid Chromatography - Ultraviolet Detection \\
PTFE & Liquid Chromatography - Mass Spectrometry \\
IS & Polytetrafluoroethylene (Teflon) \\
MRM & Internal Standard \\
KV & Multiple Reaction Monitoring \\
TIC & Kilo Volt \\
CQA & Total lon Chromatograms \\
WLS & Caffeoylquinic Acids \\
OLS & Weighted Least Squares \\
LOD & Ordinary Least Squares \\
LOQ & Limit of Detection \\
ABC & Limit of Quantitation \\
ME & American Blended Cigarette \\
KRC & Matrix Effects \\
RSD & Kentucky Reference Cigarette \\
\hline & Relative Standard Deviation \\
\hline
\end{tabular}

\section{INTRODUCTION}

The U.S. Alcohol and Tobacco Tax and Trade Bureau (TTB) is responsible for determining proper tax classification of tobacco products. This classification will determine the amount of tax that is applied to the finished consumer product. Tobacco products in the U.S. may fall into several taxable categories including cigars, cigarettes, snuff, chewing tobacco, pipe tobacco and roll-your-own. These product types are defined, to a great extent, by the types of processed tobacco used to manufacture them.

Green tobacco leaves are transformed into material suitable for incorporation into consumer products through a drying process known as curing. Different types of tobacco (Bright, Burley, Oriental) are cured using different methods (Bright from flue-curing, Burley from air-curing, Oriental from sun-curing) to achieve distinct organoleptic properties in the dried leaf or the smoke produced from burning the dried leaf. Additionally, significant variations in the chemical profile of the dried leaf can be observed between leaves processed under different curing conditions.

Some variations in leaf chemistry that result from differences in curing conditions manifest as color differences in cured leaves. The chemical changes leading to color differences between flue-cured and air-cured tobaccos result from chlorophyll decomposition, which leads to yellowing in flue-cured tobaccos, and phenolic oxidation, which leads to browning in air-cured tobaccos (1). Browning in tobacco is an enzymatic process wherein polyphenol 
oxidase (PPO) and peroxidases catalyze the oxidation of polyphenols such as chlorogenic acid to form brown pigments (2). Browning occurs during air-curing because of the mild conditions imposed by the process. Air-curing requires no artificial heat unless seasonal temperature fluctuations require it to maintain curing conditions. Enzymatic browning does not occur to an appreciable extent in flue-cured tobaccos because of enzyme deactivation at the high temperature of the curing process. This leads to the golden-yellow to orange colors observed in the cured leaves. Similarly, Oriental or sun-cured tobaccos, which are dried under direct exposure to sunlight, are characterized by leaves ranging in color from yellow to orange. This coloration suggests that the enzymatic process that leads to browning in air-cured leaves is inhibited in sun-cured leaves. This is interesting because, similar to aircuring, sun-curing is completed under ambient conditions. Tobacco contains approximately 100 compounds which can be classified as phenolics, most of which are present in minute amounts (3). As the name implies, polyphenols contain multiple phenolic hydroxyl groups. The most abundant polyhenols found in tobacco are chlorogenic acid and rutin. In flue-cured tobaccos, chlorogenic acid is the predominant polyphenol and has been found at levels as high as $3 \%$ in the leaf (3). There are three isomers of chlorogenic acid present in tobacco $(4,5)$, the most abundant being 3-O-caffeoylquinic acid, which is the isomer commonly referred to as chlorogenic acid. Rutin (quercetin3-O-rutinoside) is the next most abundant polyphenol and is typically found at levels around $1 \%$ in flue-cured tobac$\cos (3)$. In contrast, air-cured tobaccos generally contain very small amounts of these compounds with total polyphenol content less than $0.5 \%(2,3)$. Furthermore, the fermentation conditions that are often applied to air-cured tobacco sustain the enzymatic processes leading to browning and results in almost complete elimination of the polyphenolic content from the leaf (6). It is important to note that pigment formation is a complex process that leads to both water-soluble and, to a greater extent, waterinsoluble fractions (6). These pigments are generally high molecular weight polymers and the proportion of soluble component appears to decrease with fermentation (2). Evidence for this can be seen in aqueous extracts of fermented and unfermented air-cured tobacco. The unfermented leaf extracts generally are golden-brown colored while the fermented leaf extracts range from light-brown to colorless.

A number of analytical methods have been developed to study polyphenols in tobacco $(4,7-9)$ and in other natural products $(10,11)$. As is often the case in the analysis of natural products, a significant amount of effort has been expended in the optimization of sample extraction conditions. In the case of tobacco, extraction conditions vary from simple agitation to ultrasound-assisted (12) and reflux extraction (13). Detailed studies of these extraction techniques $(4,8)$ demonstrated that the more severe conditions promoted degradation of the polyphenols. The significant body of work in the literature regarding the extraction of polyphenols from plant matrices has led to some consistency on key issues relating to the conditions of the extraction. Perhaps the most significant is the solvent system, which is usually a methanol/water mixture (14). The ratio of methanol to water varies but, when tobacco is the plant matrix, the solvent mixture is generally between $60 \%$ and $80 \%$ methanol $(12,13,15,16)$. Additionally, it was found that extraction temperatures above $60^{\circ} \mathrm{C}$ should be avoided and degassed extraction solvents should be used with pressurized liquid extraction (PLE) due to the chemical reactivity of the phenolics $(17,18)$.

The analysis of polyphenols from botanical sources, particularly solanaceous plants like tobacco, using mass spectrometry has been the subject of a significant amount of research and ESI-MS/MS has been used to generate fragmentation data on major and minor polyphenols found in plant extracts (19-26). Similarities in the fragmentation of the three isomers of chlorogenic acid are well documented (19-22) and emphasize the need for the optimized chromatographic separation presented here to both distinguish and quantify these compounds in tobacco extracts. In the work discussed here, a validated method for the analysis of polyphenols in cured tobacco leaf as well as tobacco fill material from cigars and cigarettes using PLE and Ultra Performance Liquid Chromatography with Electrospray Ionization - Tandem Mass Spectrometric Detection (UPLC-ESI-MS/MS) is presented. This method was optimized to quantify the amounts of six prominent tobacco polyphenols: chlorogenic acid (3-O-caffeoylquinic acid or 3-CQA), cryptochlorogenic acid (4- $O$-caffeoylquinic acid or 4-CQA), neochlorogenic acid (5-O-caffeoylquinic acid or 5-CQA), nicotiflorin (kaempferol 3-O-rutinoside), rutin (quercetin 3-O-rutinoside), and scopoletin (6-methoxy-7hydroxycoumarin).

Considering that the mandate of the TTB is to apply tax rates to finished tobacco products, the scope of application of this analytical method should be relatively straightforward. However, the difficulty in designing an analytical method for tobacco products, even those that fall under well-established tax classification categories, is easily underestimated. The TTB receives a wide variety of consumer products from both domestic and international customers with little or no information regarding the processing or additives used in the manufacturing of these products. When designing analytical methods, it is necessary to assume that any sample can contain additives that are capable of interfering with the analysis. This is where the value of mass spectrometry is made apparent. When combined with liquid chromatography, it offers superior selectivity when compared to LC-UV, which has been used in the past to study tobacco polyphenols (4).

\section{EXPERIMENTAL}

\section{Reagents and raw materials}

Chlorogenic acid, cryptochlorogenic acid, neochlorogenic acid, rutin, and scopoletin were purchased from SigmaAldrich (St. Louis, MO, USA). Nicotiflorin was purchased from Indofine (Hillsborough, NJ, USA). ${ }^{13} \mathrm{C}_{3}$-labeled chlorogenic acid (purity 98\%, isotopic purity $>98 \%$, MW $357.28 \mathrm{Da}$ ), ${ }^{2} \mathrm{H}_{3}$-labeled rutin (purity $97.3 \%$, MW $\left({ }^{2} \mathrm{H}_{3}\right)$ $613.53 \mathrm{Da}$, distribution of isotopes includes ${ }^{2} \mathrm{H}_{0} 0 \%,{ }^{2} \mathrm{H}_{1}=$ $2.5 \%,{ }^{2} \mathrm{H}_{2}=18.2 \%,{ }^{2} \mathrm{H}_{3}=49.5 \%,{ }^{2} \mathrm{H}_{4}=29.9 \%$ ), and ${ }^{2} \mathrm{H}_{3}$ labeled scopoletin (purity $>99 \%$, isotopic purity $>98 \%$, 
MW 195.18 Da) were purchased from PharmAgra Labs (Brevard, NC, USA). Methanol (Optima Grade, Fisher Chemical, (Pittsburgh, PA, USA)) and high purity water (18.2 $\mathrm{M} \Omega$ ) were used to perform extractions and prepare samples and calibrants for analysis. LC-MS grade formic acid was purchased from Sigma-Aldrich and was used to prepare mobile phases for chromatographic analysis. Tobacco product samples were purchased by laboratory staff from local and online retailers as they were available. No sampling strategy was employed other than to ensure that we included a variety of product types. Kentucky Reference Cigarette 3R4F was purchased from The University of Kentucky (Center for Tobacco Reference Products, Kentucky Tobacco Research \& Development Center, KY, USA). Tobacco leaf samples were obtained from Universal Leaf Tobacco Company (Richmond, VA, USA).

\section{Preparation of standards}

A solution of $40 \%(v / v)$ methanol in water containing the three stable isotope-labeled internal standards was used as the diluent for all calibrants and tobacco extracts. The concentrations of the internal standards in the IS diluent were $25 \mu \mathrm{g} / \mathrm{kg}$ for ${ }^{2} \mathrm{H}_{3}$-scopoletin, $220 \mu \mathrm{g} / \mathrm{kg}$ for ${ }^{2} \mathrm{H}_{3}$-rutin, and $240 \mu \mathrm{g} / \mathrm{kg}$ for ${ }^{13} \mathrm{C}_{3}$-chlorogenic acid. All calibrants were filtered using syringe filters with $0.2 \mu \mathrm{m}$ PTFE membranes (VWR International, (West Chester, PA, USA)) prior to analysis. Eight point calibration curves were prepared for each analyte in the ranges shown in Table 4.

\section{Preparation of samples}

Extractions were performed using a Thermo Scientific Dionex ASE 350 Accelerated Solvent Extractor system (Thermo Fisher, Waltham, MA, USA). Prior to extraction, all tobacco samples were ground to 20 mesh using a Wiley Mini-Mill (Thomas Scientific, Swedesboro, NJ, USA). Ground samples were stored at $-20{ }^{\circ} \mathrm{C}$ in sealed polypropylene containers. For the ASE 350 extractions, $80 \mathrm{mg}$ to $120 \mathrm{mg}$ of ground tobacco leaf or tobacco product and an equivalent weight of diatomaceous earth were added to the extraction cell. The remaining volume in the cell was filled with Ottawa Sand, Standard 20-30 mesh. The extraction solvents, which were methanol and water, were prepared by vacuum degassing with sonication for $30 \mathrm{~min}$. Extractions were performed using the conditions described in Table 1. Raw extracts from the ASE 350 were filtered using a syringe filter with a $0.2 \mu \mathrm{m}$ PTFE membrane. The filtered extracts were first diluted 1:1 with high purity water followed by a second dilution step (1:100) in the IS diluent for analysis, which equates to a 200 -fold dilution. An alternate dilution scheme for samples with very low levels of polyphenols adjusted the second dilution step to a ratio of 3:100 in the IS diluent, which equates to a 66-fold dilution. For the lower dilution ratio samples, preparation of the calibration standards was adjusted to accommodate the alternate dilution scheme.
Table 1. Extraction parameters for tobacco samples using the Dionex ASE 350 Accelerated Solvent Extractor.

\begin{tabular}{ll}
\hline \multicolumn{2}{l}{ ASE 350 extraction parameters } \\
\hline Extraction temperature & $55^{\circ} \mathrm{C}$ \\
Heat & $5 \mathrm{~min}$ \\
Static time & $3 \mathrm{~min}$ \\
Cycles & 5 \\
Run time & $15 \mathrm{~min}$ \\
Rinse volume & $40 \%$ \\
Purge & $60 \mathrm{sec}$ \\
Methanol & $80 \%$ \\
Water & $20 \%$ \\
Cell type & stainless steel \\
Cell volume & $10 \mathrm{~mL}$ \\
Filter & glass fiber \\
\hline
\end{tabular}

Table 2. Gradient conditions for optimized UPLC separation of six polyphenols from tobacco. A flow rate of $0.4 \mathrm{~mL} / \mathrm{min}$ was used throughout the gradient.

\begin{tabular}{lcc}
\hline Time $(\mathrm{min})$ & \% Mobile phase A & \% Mobile phase B \\
\hline 0.00 & 90.0 & 10.0 \\
2.00 & 84.0 & 16.0 \\
3.30 & 60.0 & 40.0 \\
4.40 & 0.0 & 100.0 \\
5.40 & 0.0 & 100.0 \\
5.50 & 90.0 & 10.0 \\
8.00 & 90.0 & 10.0 \\
\hline
\end{tabular}

\section{UPLC-ESI-MS/MS method}

Analyses were performed using a Waters ACQUITY UPLC I-Class System interfaced with a Waters Xevo TQ-S tandem mass spectrometer (Milford, MA, USA). The column chosen for this analysis was a Waters Acquity UPLC BEH C18 Column, $1.7 \mu \mathrm{m}$ particle size, $2.1 \mathrm{~mm} \times$ $100 \mathrm{~mm}$. The column operating temperature was $30^{\circ} \mathrm{C}$ and the flow rate was $0.4 \mathrm{~mL} / \mathrm{min}$. Aqueous mobile phase (A) was $0.3 \%$ formic acid $(v / v)$ in $18.2 \mathrm{M} \Omega$ water and the organic mobile phase (B) was $0.3 \%$ formic acid $(v / v)$ in methanol. The injection volume was $2 \mu \mathrm{L}$ for all standards and samples. The gradient conditions are shown in Table 2. Mass spectrometry experiments were run in negative ion mode with a capillary voltage of $2.00 \mathrm{kV}$. The source and desolvation temperatures were $150{ }^{\circ} \mathrm{C}$ and $500^{\circ} \mathrm{C}$, respectively. The desolvation gas flow was set at $900 \mathrm{~L} / \mathrm{h}$. Conditions for Multiple Reaction Monitoring (MRM) experiments were obtained by conducting infusion analysis of neat solutions of the six analytes and three stable isotope labelled internal standards. The MRM experimental conditions are listed in Table 3. An overlay of total ion chromatograms (TIC) for chlorogenic acid, cryptochlorogenic acid, neochlorogenic acid, rutin, nicotiflorin, and scopoletin using the optimized conditions described above is shown in Figure 1.

Although baseline resolution for every analyte was not required due to the mass selectivity of the detection method, it was required for the three caffeoylquinic acids since they share the same parent ion mass and similar fragmentation patterns. Figure 2 shows the results of MRM experiments for 3-, 4-, and 5-CQA. The critical separation 
Table 3. Conditions for Multiple Reaction Monitoring (MRM) experiments for six analytes and three internal standards analyzed using the optimized conditions of the analytical method. Fragments marked with an asterisk $\left(^{*}\right)$ were used for quantitation. Where available, the second fragment was used for confirmation.

\begin{tabular}{|c|c|c|c|c|}
\hline & $\begin{array}{l}\text { Parent } \\
\text { (Da) }\end{array}$ & $\begin{array}{l}\text { Daughter } \\
\text { (Da) }\end{array}$ & $\begin{array}{l}\text { Cone } \\
(\mathrm{V})\end{array}$ & $\begin{array}{l}\text { Coll } \\
(\mathrm{eV})\end{array}$ \\
\hline 5-CQA & 353.2 & $\begin{array}{l}179.2 \\
191.2\end{array}$ & 8 & $\begin{array}{l}20 \\
18\end{array}$ \\
\hline CQA & 353.2 & 191.2 * & 6 & 18 \\
\hline 3-CQA $-{ }^{13} \mathrm{C}_{3}$ & 356.2 & 191.2 * & 6 & 18 \\
\hline 4-CQA & 353.2 & $\begin{array}{l}191.2 \\
173.2 \text { * }\end{array}$ & 8 & 18 \\
\hline Scopoletin & 191.1 & $\begin{array}{l}148.1 \\
176.2 \text { * }\end{array}$ & 6 & 14 \\
\hline Scopoletin $-{ }^{2} \mathrm{H}_{3}$ & 194.1 & $176.2^{*}$ & 6 & 14 \\
\hline Rutin & 609.4 & $\begin{array}{l}300.4 \\
271.3^{*}\end{array}$ & 86 & $\begin{array}{l}54 \\
34\end{array}$ \\
\hline Rutin $-{ }^{2} \mathrm{H}_{3}$ & 612.4 & 303.4 * & 86 & 54 \\
\hline Nicotiflorin & 593.7 & $\begin{array}{l}285.4 \\
255.3\end{array}$ & 15 & 53 \\
\hline
\end{tabular}

for this experiment involves 3- and 4-CQA, which commanded much of the attention during optimization. Although the 173.2 Da fragment for 4-CQA appears to be almost exclusive to 4-CQA, the major fragment for 3-CQA, which is $191.2 \mathrm{Da}$, also appears to a significant extent in the fragmentation data for 4-CQA. In fact, there were no examples of fragments exclusive to 3-CQA relative to 4-CQA. Without baseline chromatographic separation of these positional isomers, there would be no way of assuring selectivity between 3-CQA and 4-CQA.

\section{Reporting results}

Internal standards were used to mitigate the effects of random errors in the analytical method. The calibration curve was plotted with the following $(\mathrm{x}, \mathrm{y})$ values using the ratio of concentrations and peak areas for calibrant and internal standard (IS):

$$
\begin{gathered}
y=\text { peak area }_{\text {calibrant }} \times \frac{\text { concentration }_{I . S .}}{\text { peak area }_{I . S .}} \\
x=\text { concentration }_{\text {calibrant }}
\end{gathered}
$$

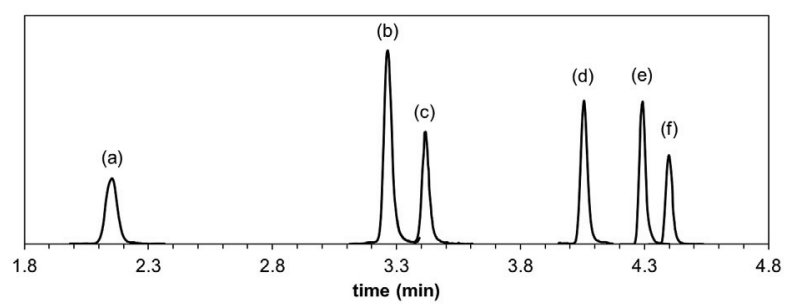

Figure 1. Overlay of 6 total ion chromatograms (TIC) from injections of calibration standard solutions. All peaks, principally the three CQA's, are well resolved. Analytes elute in the order 5-CQA (a), 3-CQA (b), 4-CQA (c), scopoletin (d), rutin (e), and nicotiflorin (f). For $3-$ and 4-CQA, a resolution value of 2.7 was achieved using the gradient conditions described in this publication.
Weighted least squares (WLS) analysis was used to determine unknown analyte concentrations from the peak area of the analyte and the peak area and concentration of the internal standard. Analyte concentrations in tobacco extracts and calibrant solutions are reported in units of micrograms per kilogram $(\mu \mathrm{g} / \mathrm{kg})$. Polyphenol content in tobacco leaf is reported in milligrams of analyte per gram of tobacco $(\mathrm{mg} / \mathrm{g})$.

\section{RESULTS AND DISCUSSION}

\section{Method validation \\ Linearity, linear range, $L O Q$, and $L O D$}

As is often the case with hyphenated techniques involving MS detection, internal standards were used to improve precision and accuracy. Stable isotope-labeled internal standards were added to the diluent solution that was used to prepare the calibrants and filtered extracts for analysis. In the analysis described here, ${ }^{2} \mathrm{H}_{3}$-labeled scopoletin was used as the internal standard for scopoletin, ${ }^{13} \mathrm{C}_{3}$-labeled 3-CQA was used for 3-CQA, 4-CQA, and 5-CQA while ${ }^{2} \mathrm{H}_{3}$-labeled rutin was used for nicotiflorin and rutin.

Linear ranges were established using eight point calibration curves for each analyte and analyzed using weighted least squares (WLS) with $1 / \mathrm{x}^{2}$ weighting. The decision to use WLS to fit the calibration curve resulted from statistical analysis of the data, employing the F-Test to determine if variances in the calibration data across the concentration range were uniform. Since ordinary least squares, or simple regression, assumes uniform variance (homoscedasticity)
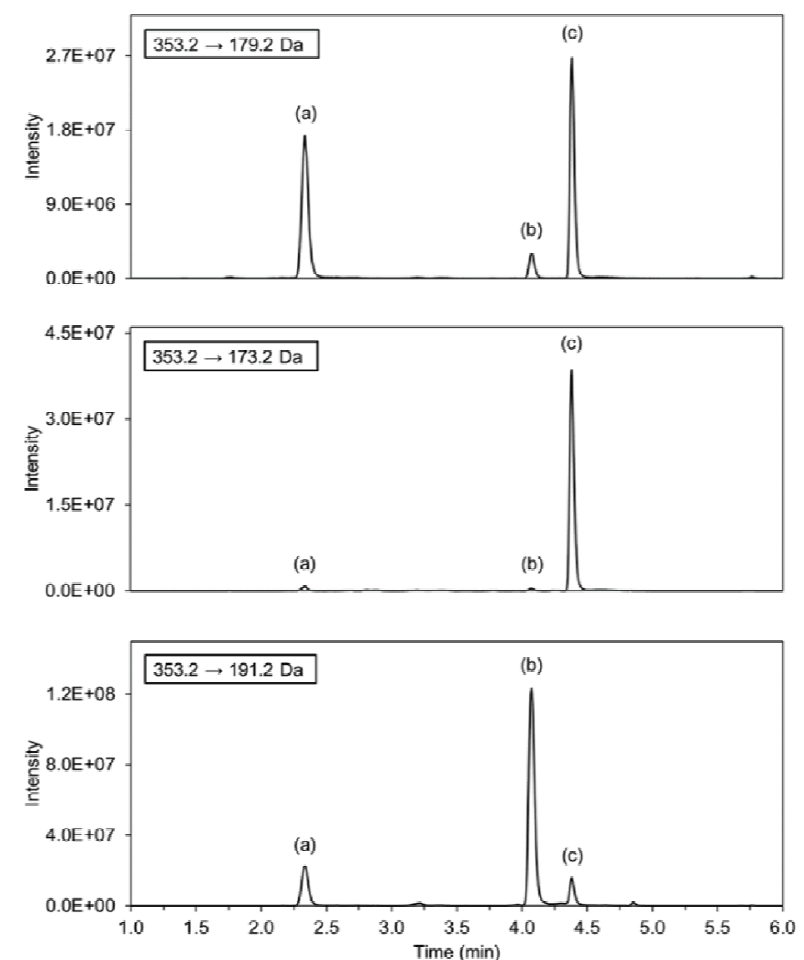

Figure 2. MRM chromatograms showing major fragments for 5-CQA (a), 3-CQA (b), and 4-CQA (c). Baseline separation of 3-CQA and 4-CQA is desirable because of the relatively strong intensities of the 191.2 Da fragment, which is a quantitation ion in this method, for both 3-CQA and 4-CQA. 
across a data set, it is important to determine if calibration data fits the model. It turned out that calibration data for all six analytes consistently exhibited unequal variance (heteroscedasticity) when analyzed with the F-test. WLS is used to compensate for heteroscedasticity when estimating the fit of the calibration data and works by assigning higher weights to calibration points known to have higher precision. The decision to weight using $1 / \mathrm{x}^{2}$ resulted from monitoring the standard error of the $y$-estimate $\left(\sigma_{\text {est }}\right)$ as the weighting exponent was changed from zero (which collapses the WLS fit to an OLS fit) to 2. Using this approach, it was found that the $1 / \mathrm{x}^{2}$ WLS fit consistently provided the lowest $\sigma_{\text {est }}$ for all six analytes. Table 4 lists the retention time, calibration range, correlation coefficient, $y$-intercept, and slope for the WLS fits for each analyte.

An extrapolation of the linear ranges from the standard curves to analyte content in an extract of tobacco samples is useful because it demonstrates the increased range provided by the alternate dilution schemes and variations in the tobacco weight. For tobacco samples weighing between 80 and $120 \mathrm{mg}$, the method is capable of detecting and quantifying the six polyphenols in the following concentration ranges (units of $\mathrm{mg} / \mathrm{g}$ ): $0.02 \rightarrow 2.8$ for scopoletin, $0.11 \rightarrow 17.9$ for rutin, $0.07 \rightarrow 7.2$ for nicotiflorin, $0.13 \rightarrow 22.4$ for 3-CQA, $0.03 \rightarrow 5.5$ for 5 -CQA, and $0.04 \rightarrow 6.9$ for $4-C Q A$. These ranges reflect both dilution ratios (66- and 200-fold) discussed previously.

The limits of quantitation (LOQ) and detection (LOD) were estimated from the statistics of the WLS fit of the calibration data and were calculated using the following equations $(27,28)$

$$
\begin{aligned}
& L O Q=10 \sigma_{y-i n t / S} \\
& L O D=3.3 \sigma_{y-i n t / S}
\end{aligned}
$$

Where $\sigma_{y \text {-int }}$ is the standard error of the y-intercept and $S$ is the slope of the calibration curve. Table 4 lists the calculated LOQs and LODs for all six calibrants.

\section{Recovery}

Recovery was assessed for loose, ground samples of cured tobacco leaf and fill material from tobacco products using the ASE 350. Successive extractions of cells containing $100 \mathrm{mg}$ of flue-cured, air-cured, sun-cured tobaccos and fill material from Kentucky Reference Cigarette 3R4F, American Blended Cigarette (ABC), large cigar, cigarillo, filter tipped little cigar, and a pipe tobacco cigar were performed. Each cell was extracted three times using the optimized extraction conditions shown in Table 1 into each of three collection vials. Each extract was analyzed and the peak areas (adjusted using the responses for the internal standards) from chromatograms of each extract were compared. Recovery was calculated by comparing the peak area of the first extraction to the sum of all three extractions for each cell. The results of these experiments are shown in Table 5 and show that extraction efficiencies for all analytes except scopoletin were generally lower for tobacco products relative to cured tobacco leaves. Most significant is the comparison of cigar-type products and air-cured leaf because both contain low levels of polyphenols. Typical chromatographic analyses for these products return peak areas that are near or below the lower limit of the quantitation range for the analytical method. This was particularly true for the large cigar results listed in Table 5, where significantly smaller peak areas were more difficult to reproduce, leading to the larger standard errors observed for all six analytes. In fact, unlike the rest of the tobacco products investigated in the recovery study, the results for all six analytes in the large cigar sample are well outside the linear range of the method. Other than the large cigar, the results of the recovery study demonstrate that extraction efficiency for the six analytes across the remaining tobacco samples is $85 \%$ or higher.

\begin{tabular}{|c|c|c|c|c|c|c|c|c|}
\hline Analyte & \begin{tabular}{|c|}
$\begin{array}{c}\text { Retention time } \\
\text { (min) }\end{array}$ \\
\end{tabular} & & $\begin{array}{l}\text { lear range } \\
(\mu \mathrm{g} / \mathrm{kg})\end{array}$ & $\begin{array}{l}\text { Correlation } \\
\text { coefficient }\end{array}$ & Slope & Intercept & $\begin{array}{c}\text { LOD } \\
(\mu \mathrm{g} / \mathrm{kg})\end{array}$ & $\begin{array}{c}\mathrm{LOQ} \\
(\mu \mathrm{g} / \mathrm{kg})\end{array}$ \\
\hline 5-CQA & 2.15 & 4 & 160 & 0.998 & 0.979 & -0.168 & 0.3 & 0.9 \\
\hline 3-CQA & 3.27 & 16 & 650 & 0.998 & 1.193 & -0.416 & 0.9 & 2.8 \\
\hline 4-CQA & 3.42 & 5 & 200 & 0.997 & 1.025 & 0.313 & 0.4 & 1.1 \\
\hline Scopoletin & 4.06 & 2 & 80 & 0.998 & 1.073 & 0.020 & 0.1 & 0.4 \\
\hline Rutin & 4.29 & 13 & 520 & 0.997 & 8.360 & 3.327 & 0.9 & 2.6 \\
\hline Nicotiflorin & 4.40 & 9 & 210 & 0.996 & 4.497 & -0.298 & 0.5 & 1.6 \\
\hline
\end{tabular}

Table 4. Chromatographic retention time, linear range, LOD, and LOQ as determined for six polyphenol analytes found in tobacco.

Table 5. Results of recovery experiments $( \pm 1$ standard deviation) for samples of tobacco leaf and fill material from tobacco products. Recovery assessed through multi-step exhaustive extractions of stainless steel cells containing loose, ground tobacco on the ASE 350 .

\begin{tabular}{l|c|c|c|c|c|c|c|c|c}
\hline Analyte & KRC 3R4F & $\begin{array}{c}\text { ABC style } \\
\text { cigarette }\end{array}$ & $\begin{array}{c}\text { Large } \\
\text { cigar }\end{array}$ & Cigarillo & $\begin{array}{c}\text { Filtered } \\
\text { little cigar }\end{array}$ & $\begin{array}{c}\text { Pipe tobacco } \\
\text { cigar }\end{array}$ & $\begin{array}{c}\text { Oriental } \\
\text { tobacco }\end{array}$ & $\begin{array}{c}\text { Flue-cured } \\
\text { tobacco }\end{array}$ & $\begin{array}{c}\text { Air-cured } \\
\text { tobacco }\end{array}$ \\
\hline 5-CQA & $97.6 \pm 0.7$ & $98.4 \pm 0.3$ & $86 \pm 8$ & $92.0 \pm 3.0$ & $93.0 \pm 1.0$ & $96.3 \pm 0.5$ & $99.2 \pm 0.1$ & $99.6 \pm 0.1$ & $98.7 \pm 0.2$ \\
3-CQA & $95.3 \pm 0.9$ & $96.3 \pm 0.3$ & $73 \pm 6$ & $86.0 \pm 2.0$ & $85.1 \pm 0.2$ & $92.4 \pm 0.4$ & $98.2 \pm 0.4$ & $99.2 \pm 0.2$ & $97.4 \pm 0.2$ \\
4-CQA & $96.7 \pm 0.7$ & $97.6 \pm 0.2$ & $80 \pm 2$ & $89.0 \pm 2.0$ & $89.1 \pm 0.5$ & $95.6 \pm 0.2$ & $98.8 \pm 0.3$ & $99.4 \pm 0.1$ & $98.1 \pm 0.2$ \\
Scopoletin & $99.7 \pm 0.4$ & $99.7 \pm 0.1$ & 100 & $99.7 \pm 0.4$ & 100 & 100 & - & $99.9 \pm 0.1$ & 100 \\
Rutin & $97.0 \pm 1.0$ & $97.5 \pm 0.4$ & $73 \pm 5$ & $91.0 \pm 1.0$ & $91.1 \pm 0.4$ & $90.0 \pm 2.0$ & $99.4 \pm 0.1$ & $99.5 \pm 0.1$ & $99.1 \pm 0.2$ \\
Nicotiflorin & $98.0 \pm 0.2$ & $98.8 \pm 0.2$ & $90 \pm 3$ & $96.3 \pm 0.4$ & $95.3 \pm 0.9$ & 100 & $99.6 \pm 0.1$ & $99.7 \pm 0.1$ & $99.5 \pm 0.2$ \\
\hline
\end{tabular}


Reduced extraction efficiencies in the tobacco product fill material studied here might be related to the processes and additives used to manufacture the products. In addition to casing sauces and humectants, many of these products contain reconstituted sheet tobacco, expanded tobacco, or expanded stems. None of these additives were present in the cured leaf samples and none of these components could have been evaluated in the recovery study due to lack of availability. When viewed from this perspective, these results shed light on the uncertainty in developing an optimized extraction method for a class of tobacco products with limited information regarding the components of any individual product. Choosing a flavored pipe tobacco cigar and several unflavored cigars (large and small) for this analysis was deliberate and intended to highlight the extremes that are encountered particularly with machinerolled cigar fill material.

Spiked recovery experiments were performed on samples of Kentucky Reference Cigarette with solutions of the six analytes. The results of these experiments are shown in Table 6

Table 6. Results of spiked recovery experiments $( \pm 1$ standard deviation) using samples of fill material from Kentucky Reference Cigarette. The tobacco was spiked with solutions of the six polyphenol analytes prior to extraction with the ASE 350 and compared to results from unspiked tobacco.

\begin{tabular}{l|r|r|c}
\hline Analyte & $\begin{array}{c}\text { Spike } \\
(\mu \mathrm{g})\end{array}$ & $\begin{array}{c}\text { Recovery } \\
(\%)\end{array}$ & $\begin{array}{c}\text { Average } \\
\text { recovery }(\%)\end{array}$ \\
\hline \multirow{3}{*}{ 5-CQA } & 42 & $95 \pm 5$ & \\
& 74 & $100 \pm 7$ & $98 \pm 4$ \\
& 106 & $99 \pm 9$ & \\
3-CQA & 137 & $95 \pm 6$ & \\
& 239 & $95 \pm 7$ & $94 \pm 3$ \\
& 342 & $91 \pm 5$ & \\
4-CQA & 49 & $94 \pm 5$ & \\
& 86 & $97 \pm 5$ & $95 \pm 3$ \\
& 123 & $94 \pm 5$ & \\
Scopoletin & 19 & $98 \pm 4$ & \\
& 34 & $102 \pm 4$ & $100 \pm 3$ \\
Rutin & 48 & $101 \pm 7$ & \\
& 130 & $97 \pm 6$ & \\
& 228 & $98 \pm 5$ & $95 \pm 3$ \\
Nicotiflorin & 326 & $92 \pm 3$ & \\
& 67 & $98 \pm 5$ & \\
\hline
\end{tabular}

The cigarette fill material was chosen because it contains quantifiable levels of all the analytes in the unspiked matrix, thus allowing for direct comparison between spiked and unspiked results. This study compared the measured concentration of the analyte in the spiked sample to the sum of the concentrations of the analyte in the unspiked tobacco and spike solution. Spiking solutions were prepared at three levels and were added to separate cells containing ground samples of 3R4F and extracted alongside unspiked tobacco sample cells. Each spike level (including the unspiked tobacco) was analyzed in triplicate for a total of 12 experiments for each analyte. Average recoveries for the spiked analytes were greater than $90 \%$ for all six of the analytes across the range of spike levels.

\section{Intermediate precision}

Intermediate precision was determined from fifteen runs of Kentucky Reference Cigarette 3R4F. Each of the fifteen runs involved extractions of $3 \mathrm{R} 4 \mathrm{~F}$ in triplicate and was carried out over a nine month period with fresh preparations of mobile phases, extraction solutions, diluents, and calibrants for each experiment. The overall statistics for the intermediate precision study are shown in Table 7.

Table 7. Intermediate precision as determined from fifteen runs of Kentucky Reference Cigarette 3R4F (lot no. V346X61B5).

\begin{tabular}{l|cc}
\hline \multirow{2}{*}{ Analyte } & \multicolumn{2}{|c}{ Concentration } \\
\cline { 2 - 3 } & Average $(\mathrm{mg} / \mathrm{g})$ & $\mathrm{RSD}(\%)$ \\
\hline 5-CQA & $0.68 \pm 0.05$ & 7.4 \\
3-CQA & $3.4 \pm 0.2$ & 5.5 \\
4-CQA & $0.94 \pm 0.06$ & 6.0 \\
Scopoletin & $0.20 \pm 0.01$ & 5.2 \\
Rutin & $2.3 \pm 0.1$ & 5.8 \\
Nicotiflorin & $0.31 \pm 0.03$ & 9.4 \\
\hline
\end{tabular}

\section{Matrix effect}

Matrix effects (ME) in ESI-MS/MS are observed when undetected co-eluting matrix components alter the ion intensity of the analyte(s) of interest. Analyte ion intensity can be suppressed or enhanced by the co-eluting component and either effect can influence the accuracy of the analytical method. To investigate $\mathrm{ME}$, triplicate extracts of KRC 3R4F, a filtered cigar, and a pipe tobacco cigar were spiked at three levels (for a total of nine experiments) and analyzed versus the spike solutions diluted in internal standard solution.

Although most tobacco samples are analyzed at a 200-fold dilution of the PLE extract, samples that are traditionally low in polyphenol content, such as cigar tobacco, require a lower dilution ratio to quantify the analytes. In these cases, a 66-fold dilution is used. Since two dilution levels are used to analyze tobacco samples, the post-extraction spike experiments were also performed at 66 - and 200 -fold dilutions.

The post-extraction spike data were analyzed by plotting the responses (corrected using the internal standards) for each analyte versus spike concentration and analyzed using linear regression. To determine if there was an observable ME in tobacco extracts for the six analytes, the slopes of the curves generated from the spiked tobacco extracts and the spiked internal standard diluent were compared $(29,30)$.

In the absence of a ME, the slopes of these curves should be equal and their quotient ( slope $_{\text {tobaccomatrix }} /$ slope $_{\text {neat solution }}$ ) should be 1. Additionally, since matrix effect is often expressed as a percentage $(31,32)$, the quotient is multiplied by 100 . In this calculation, a value $<100 \%$ suggests signal suppression while a value $>100 \%$ suggests enhancement. The results of this analysis are shown along with the standard error of each determination in Table 8 for KRC 3R4F, a filtered cigar, and a pipe tobacco cigar. The table lists the average ME for triplicate runs of the multilevel spike experiments over the stated ranges.

For the 200-fold dilution experiments, it appears that any observable ME across the range of analytes is virtually 
Table 8. Assessment of matrix effect (ME) from multilevel spike experiments for six polyphenol analytes. The table lists the average ME for triplicate runs of each analyte over the stated ranges ( \pm 1 standard deviation). The correlation coefficients result from the linear regression fit of the spiked tobacco data. The experiments were done at two dilutions (66- and 200-fold) of each tobacco extract.

\begin{tabular}{|c|c|c|c|c|c|c|c|}
\hline & & 5-CQA & 3-CQA & 4-CQA & Scopoletin & Rutin & Nicotiflorin \\
\hline $200 \times$ dilution & $\begin{array}{l}\text { Spike range } \\
(\mu \mathrm{g} / \mathrm{kg})\end{array}$ & $13 \rightarrow 130$ & $40 \rightarrow 400$ & $12 \rightarrow 120$ & $5 \rightarrow 50$ & $31 \rightarrow 310$ & $14 \rightarrow 140$ \\
\hline \multirow{2}{*}{ KRC 3R4F } & ME (\%) & $102 \pm 3$ & $101 \pm 3$ & $103 \pm 3$ & $97 \pm 4$ & $98 \pm 2$ & $101 \pm 2$ \\
\hline & $r^{2}$ & 0.9984 & 0.9971 & 0.9983 & 0.9980 & 0.9991 & 0.9991 \\
\hline \multirow{2}{*}{ Pipe tobacco cigar } & $\mathrm{ME}(\%)$ & $100 \pm 3$ & $97 \pm 2$ & $98 \pm 4$ & $100 \pm 3$ & $101 \pm 2$ & $99 \pm 2$ \\
\hline & $r^{2}$ & 0.9994 & 0.9994 & 0.9977 & 0.9985 & 0.9996 & 0.9997 \\
\hline \multirow{2}{*}{ Filtered cigar } & ME (\%) & $103 \pm 5$ & $100 \pm 3$ & $98 \pm 3$ & $101 \pm 2$ & $101 \pm 3$ & $100 \pm 4$ \\
\hline & $r^{2}$ & 0.9971 & 0.9989 & 0.9987 & 0.9993 & 0.9982 & 0.9979 \\
\hline $66 \times$ dilution & $\begin{array}{l}\text { Spike range } \\
(\mu \mathrm{g} / \mathrm{kg})\end{array}$ & $11 \rightarrow 110$ & $35 \rightarrow 350$ & $12 \rightarrow 120$ & $6 \rightarrow 60$ & $30 \rightarrow 300$ & $12 \rightarrow 120$ \\
\hline \multirow{2}{*}{ KRC 3R4F } & $\mathrm{ME}(\%)$ & $100 \pm 3$ & $95 \pm 4$ & $91 \pm 3$ & $104 \pm 2$ & $96 \pm 6$ & $94 \pm 4$ \\
\hline & $r^{2}$ & 0.9986 & 0.9963 & 0.9972 & 0.9993 & 0.9937 & 0.9975 \\
\hline \multirow{2}{*}{ Pipe tobacco cigar } & ME (\%) & $104 \pm 1$ & $102 \pm 1$ & $99 \pm 2$ & $99 \pm 2$ & $100 \pm 2$ & $91 \pm 2$ \\
\hline & $r^{2}$ & 0.9998 & 0.9996 & 0.9996 & 0.9996 & 0.9997 & 0.9997 \\
\hline \multirow{2}{*}{ Filtered cigar } & $\mathrm{ME}(\%)$ & $100 \pm 2$ & $101 \pm 2$ & $98 \pm 2$ & $102 \pm 1$ & $100 \pm 3$ & $99 \pm 3$ \\
\hline & $r^{2}$ & 0.9993 & 0.9994 & 0.9989 & 0.9998 & 0.9978 & 0.9984 \\
\hline
\end{tabular}

indistinguishable from $100 \%$ (within the error of each determination). With respect to the 66-fold dilution experiments, whereas the analytes in the filtered cigar extracts did not show significant $\mathrm{ME}$, some suppression was observed for 3-CQA, 4-CQA, and for nicotiflorin in $\mathrm{KRC} 3 \mathrm{R} 4 \mathrm{~F}$ as well as nicotiflorin in extracts of pipe tobacco cigar. Additionally, some signal enhancement was observed for 5-CQA in pipe tobacco cigar extracts and for scopoletin in KRC 3R4F. Signal suppression or enhancement might be expected for 4-CQA, 5-CQA, and nicotiflorin because the analysis relies on stable isotope labelled internal standards that are not matched to the native form of the analyte and do not co-elute with the analyte. Although the observable matrix effect across all analytes at the 66-fold dilution level is relatively small, there is clearly an advantage to employing the 200 -fold dilution level. With respect to experiments run on the tobacco leaf and tobacco product sample sets, the lower dilution ratio was used when the detector response for an analyte was below the quantitation range of the method, a situation that was often encountered with cigar tobaccos.

\section{Analysis of tobacco leaf and tobacco product samples}

Following method validation, a number of tobacco leaf and tobacco product samples were analyzed for polyphenol content. Table 9 lists the results for the 6 polyphenol analytes in nine of each of three types of tobacco leaves; flue-cured, air-cured, and Oriental (sun-cured). Table 10 lists the results for fill material from 15 domestic cigarettes, 20 filtered cigars, 6 machine rolled cigars/ cigarillos, and 4 pipe tobacco cigars. It is clear from the results shown in Tables 9 and 10 that many data points were below the quantitation limit (BQL) of the method. With the exception of the scopoletin levels in Oriental tobaccos, samples containing analytes that were often too low to quantify were either air-cured tobacco leaves or products traditionally manufactured with air-cured tobaccos, which includes machine-rolled, filtered, and pipe tobacco cigars. It is important to point out that the dilution ratios and tobacco sample weights were manipulated to increase the response of each analyte in all of the machinerolled and filtered cigars. Although analytes in some of the cigar and air-cured leaf samples could be quantified at lower levels by adjusting the linear ranges of the calibration curves, in many cases the instrument responses were simply too low to quantify without significant changes to the sample preparation steps. It is also important to note that we were able to maintain simplicity in sample treatment because the sensitivity of the detector allowed us to use high dilution ratios for the extracts. The intended goal being that we could minimize ME without resorting to more complex sample treatment such as SPE, which is expensive on a per-sample basis and is time consuming. Figure 3 shows the results listed in Table 9 plotted as total caffeoylquinic acids (as 3-, 4-, and 5-CQA), total flavonoid glycosides (as rutin and nicotiflorin), and scopoletin in each leaf type. The trends shown in Figure 3 for the CQAs and flavonoid glycosides in air and flue-cured leaves reflect the current understanding of the fate of the polyphenols under each curing regimen. As was discussed previously, flue-cured tobaccos generally contain much higher levels of the CQAs and rutin than air-cured tobaccos. Given that sun-curing is done under ambient conditions, it might be reasonable to assume that the resulting polyphenol content of Oriental tobacco would resemble that of air-cured tobacco. However, the results in Figure 3 demonstrate that the polyphenol profile more closely resembles a flue-cured tobacco.

Figure 3 also shows the results listed in Table 10 for cigars and cigarettes plotted as total caffeoylquinic acids (as 3-, 4-, and 5-CQA), total flavonoid glycosides (as rutin and nicotiflorin), and scopoletin. In general, the trends shown in Figure 3 for the polyphenol content of the various cigar and cigarette products reflect the type(s) of cured tobacco traditionally used in each type of product. Additionally, relatively uniform and complimentary trends in levels of the CQAs, scopoletin, and the flavonoid glycosides were observed with the tobacco products. However, this was not the case for the leaf material, where the levels of the flavonoid glycosides and scopoletin do not correlate well with the level of the CQAs. It is important to point out that the leaf material used in this study was unprocessed (beyond the point of curing) and came to our laboratory directly from the country of origin. Additionally, details such as leaf position on the stalk and an 
Table 9. Tabulation of results of analysis of 6 polyphenols from 27 ground samples of whole tobacco leaf. Each data point represents the average results ( \pm 1 standard deviation) from triplicate analyses of ground tobacco samples. The regional assignments for each sample are not intended to attribute regiospecific significance to the results. This information is presented to demonstrate the diversity of sampling for this study.

\begin{tabular}{|c|c|c|c|c|c|c|c|}
\hline Type & $\begin{array}{c}\text { Country / } \\
\text { region }\end{array}$ & $\begin{array}{l}5-C Q A \\
(\mathrm{mg} / \mathrm{g})\end{array}$ & $\begin{array}{l}3-C Q A \\
(\mathrm{mg} / \mathrm{g})\end{array}$ & $\begin{array}{l}\text { 4-CQA } \\
(\mathrm{mg} / \mathrm{g})\end{array}$ & $\begin{array}{l}\text { Scopoletin } \\
(\mathrm{mg} / \mathrm{g})\end{array}$ & $\begin{array}{l}\text { Rutin } \\
(\mathrm{mg} / \mathrm{g})\end{array}$ & $\begin{array}{c}\text { Nicotiflorin } \\
(\mathrm{mg} / \mathrm{g})\end{array}$ \\
\hline \multirow[t]{9}{*}{ Flue-cured } & E Poland * & $2.3 \pm 0.1$ & $24.3 \pm 0.8$ & $4.1 \pm 0.1$ & $0.060 \pm 0.001$ & $8.5 \pm 0.2$ & $0.96 \pm 0.03$ \\
\hline & Malawi & $2.7 \pm 0.1$ & $19.6 \pm 0.3$ & $3.74 \pm 0.06$ & $0.24 \pm 0.01$ & $13.28 \pm 0.04$ & $0.91 \pm 0.01$ \\
\hline & Tanzania & $2.00 \pm 0.02$ & $16.5 \pm 0.3$ & $2.96 \pm 0.02$ & $0.361 \pm 0.009$ & $11.7 \pm 0.2$ & $0.83 \pm 0.03$ \\
\hline & E Hungary & $2.32 \pm 0.08$ & $10.0 \pm 0.3$ & $2.6 \pm 0.1$ & $0.117 \pm 0.006$ & $5.8 \pm 0.2$ & $0.59 \pm 0.02$ \\
\hline & Argentina & $2.0 \pm 0.1$ & $9.7 \pm 0.2$ & $2.13 \pm 0.08$ & $0.281 \pm 0.009$ & $8.1 \pm 0.2$ & $0.88 \pm 0.04$ \\
\hline & S Brazil & $1.90 \pm 0.05$ & $9.0 \pm 0.2$ & $2.21 \pm 0.06$ & $0.45 \pm 0.01$ & $8.8 \pm 0.4$ & $0.57 \pm 0.02$ \\
\hline & Philippines & $1.79 \pm 0.07$ & $8.62 \pm 0.09$ & $2.46 \pm 0.03$ & $0.297 \pm 0.005$ & $5.7 \pm 0.2$ & $0.51 \pm 0.02$ \\
\hline & W Spain & $1.29 \pm 0.06$ & $7.5 \pm 0.1$ & $1.52 \pm 0.02$ & $0.096 \pm 0.004$ & $6.95 \pm 0.09$ & $0.48 \pm 0.01$ \\
\hline & Zimbabwe & $1.22 \pm 0.08$ & $6.6 \pm 0.2$ & $1.543 \pm 0.006$ & $0.57 \pm 0.02$ & $7.3 \pm 0.3$ & $0.59 \pm 0.02$ \\
\hline \multirow[t]{9}{*}{ Oriental } & Greece & $2.04 \pm 0.04$ & $10.2 \pm 0.2$ & $2.77 \pm 0.07$ & BQL & $10.6 \pm 0.1$ & $1.59 \pm 0.03$ \\
\hline & Turkey & $1.70 \pm 0.03$ & $8.9 \pm 0.1$ & $2.5 \pm 0.1$ & BQL & $8.1 \pm 0.4$ & $1.5 \pm 0.1$ \\
\hline & Macedonia & $1.71 \pm 0.08$ & $6.9 \pm 0.2$ & $2.35 \pm 0.09$ & BQL & $10.0 \pm 0.4$ & $1.75 \pm 0.01$ \\
\hline & Macedonia & $1.404 \pm 0.007$ & $5.6 \pm 0.1$ & $1.92 \pm 0.07$ & $B Q L$ & $8.4 \pm 0.2$ & $1.22 \pm 0.02$ \\
\hline & Turkey & $1.22 \pm 0.03$ & $5.3 \pm 0.1$ & $1.81 \pm 0.03$ & $B Q L$ & $6.5 \pm 0.3$ & $1.36 \pm 0.09$ \\
\hline & Bulgaria & $1.30 \pm 0.01$ & $4.9 \pm 0.1$ & $2.30 \pm 0.07$ & BQL & $7.0 \pm 0.1$ & $1.38 \pm 0.03$ \\
\hline & Macedonia & $1.23 \pm 0.03$ & $4.8 \pm 0.2$ & $1.74 \pm 0.02$ & BQL & $7.4 \pm 0.4$ & $1.38 \pm 0.08$ \\
\hline & Greece & $1.082 \pm 0.005$ & $4.38 \pm 0.07$ & $1.56 \pm 0.02$ & BQL & $5.4 \pm 0.2$ & $1.21 \pm 0.09$ \\
\hline & Turkey & $0.20 \pm 0.02$ & $1.08 \pm 0.04$ & $0.338 \pm 0.006$ & BQL & $2.51 \pm 0.07$ & $0.59 \pm 0.02$ \\
\hline \multirow[t]{6}{*}{ Air-cured } & Philippines & BQL & $0.55 \pm 0.02$ & $0.120 \pm 0.009$ & $0.065 \pm 0.002$ & $1.99 \pm 0.06$ & $0.364 \pm 0.008$ \\
\hline & S Brazil & BQL & BQL & $0.11 \pm 0.01$ & $0.055 \pm 0.001$ & $1.32 \pm 0.06$ & $0.286 \pm 0.003$ \\
\hline & S Poland & BQL & BQL & BQL & $0.071 \pm 0.004$ & $1.19 \pm 0.01$ & $0.28 \pm 0.01$ \\
\hline & S Brazil & BQL & BQL & BQL & BQL & $0.82 \pm 0.02$ & $0.18 \pm 0.01$ \\
\hline & Argentina & BQL & BQL & BQL & BQL & $0.61 \pm 0.07$ & $0.12 \pm 0.01$ \\
\hline & S Italy & BQL & BQL & BQL & BQL & $0.61 \pm 0.02$ & BQL \\
\hline \multirow{3}{*}{ Dark air-cured } & Philippines & $0.094 \pm 0.007$ & $0.42 \pm 0.02$ & $0.15 \pm 0.01$ & BQL & $0.92 \pm 0.09$ & $0.18 \pm 0.02$ \\
\hline & Guatemala & BQL & BQL & BQL & $0.10 \pm 0.03$ & $0.97 \pm 0.06$ & $0.20 \pm 0.01$ \\
\hline & S Poland & BQL & BQL & BQL & $0.205 \pm 0.005$ & BQL & BQL \\
\hline
\end{tabular}

* Sample weight was $<80 \mathrm{mg}$ to ensure that the raw data was within the linear range of the method for each analyte

explanation of the leaf grading system were not shared by the leaf supplier. Leaf grading sets quality criteria for selection of raw material in the manufacture of tobacco products. A significant factor in leaf grading is color, which has been previously established to be linked to polyphenol content (3). The inability to control grading as a variable in the selection of leaf samples for this analysis might account for the low correlation between the CQAs, flavonoid glycosides, and scopoletin described above. Figure 4 shows the distribution of caffeoylquinic acids in the tobacco products and tobacco leaf shown in Tables 9 and 10 . Generally, the trend is 3-CQA $>>4-\mathrm{CQA}>5-\mathrm{CQA}$ in cigarettes and cigars as well as flue-cured, air-cured, and Oriental tobaccos. The relative ratios of 3-, 4-, and 5CQA in flue-cured tobacco shown in Figure 4 are consistent with levels found in the literature for another fluecured tobacco (4). A notable observation in this plot is the variation of the ratio between 3-CQA and the two minor isomers. There appears to be some consistency in the differences in the relative ratios for the CQA's in cigarettes and flue-cured tobacco relative to the three types of cigar products, which are generally made from air-cured tobaccos, shown in Figure 4. However, it must also be noted that this observation, particularly as it pertains to the tobacco products, will require further study.

As was indicated previously, sample collection for the analyses discussed in this paper was driven by product availability and an interest in selecting a variety of product types. Since an opportunistic sampling strategy was employed, it is important to stress that the results generated from the analysis of tobacco products are intended only to demonstrate the utility of this analytical method. This means that an observation like the precipitous drop in chlorogenic acid content between U.S. domestic cigarette brands and filtered cigars shown in Table 10 might be an artifact of the sampling procedure.

\section{CONCLUSIONS}

A method that uses PLE and Ultra Performance Liquid Chromatography with Electrospray Ionization - Tandem Mass Spectrometric Detection (UPLC-ESI-MS/MS) for the determination of six polyphenols in cured tobacco leaf as well as tobacco fill material from cigars and cigarettes was developed and validated. The method uses PLE to ensure consistent and high analyte recoveries from a variety of tobacco product matrices. The method can be used to quantitate 6 polyphenol analytes in tobacco samples over 2 orders of magnitude in concentration. However, sample preparation steps were intended to maintain simplicity and efficiency while simultaneously 
Table 10. Tabulation of results of analysis of $\mathbf{6}$ polyphenols from $\mathbf{4 3}$ tobacco products. Each data point represents the average results from triplicate analyses of ground tobacco samples ( \pm 1 standard deviation).

\begin{tabular}{|c|c|c|c|c|c|c|c|}
\hline Product & & $\begin{array}{l}5-C Q A \\
(\mathrm{mg} / \mathrm{g}) \\
\end{array}$ & $\begin{array}{l}3-C Q A \\
(\mathrm{mg} / \mathrm{g})\end{array}$ & $\begin{array}{r}4-C Q A \\
(\mathrm{mg} / \mathrm{g}) \\
\end{array}$ & $\begin{array}{c}\text { Scopoletin } \\
(\mathrm{mg} / \mathrm{g})\end{array}$ & $\begin{array}{c}\text { Rutin } \\
\text { (mg / g) }\end{array}$ & $\begin{array}{c}\text { Nicotiflorin } \\
(\mathrm{mg} / \mathrm{g})\end{array}$ \\
\hline $\mathrm{KRC} 3 \mathrm{R} 4 \mathrm{~F}$ & 1 & $0.84 \pm 0.05$ & $4.1 \pm 0.2$ & $1.15 \pm 0.06$ & $0.245 \pm 0.009$ & $2.9 \pm 0.1$ & $0.39 \pm 0.03$ \\
\hline KRC 1R5F & 2 & $0.400 \pm 0.005$ & $1.83 \pm 0.02$ & $0.60 \pm 0.01$ & $0.133 \pm 0.002$ & $1.13 \pm 0.05$ & $0.16 \pm 0.02$ \\
\hline \multirow{11}{*}{$\begin{array}{l}\text { U.S. domestic } \\
\text { cigarette } \\
\text { brands }\end{array}$} & 3 & $1.29 \pm 0.05$ & $6.8 \pm 0.3$ & $1.70 \pm 0.08$ & $0.64 \pm 0.02$ & $5.1 \pm 0.2$ & $0.39 \pm 0.01$ \\
\hline & 4 & $0.910 \pm 0.007$ & $4.41 \pm 0.06$ & $1.23 \pm 0.03$ & $0.256 \pm 0.009$ & $3.35 \pm 0.04$ & $0.373 \pm 0.009$ \\
\hline & 5 & $0.85 \pm 0.01$ & $4.4 \pm 0.1$ & $1.117 \pm 0.009$ & $0.30 \pm 0.02$ & $3.27 \pm 0.08$ & $0.36 \pm 0.06$ \\
\hline & 6 & $0.994 \pm 0.008$ & $4.26 \pm 0.04$ & $1.348 \pm 0.008$ & $0.279 \pm 0.001$ & $3.34 \pm 0.05$ & $0.367 \pm 0.008$ \\
\hline & 7 & $0.97 \pm 0.02$ & $4.10 \pm 0.06$ & $1.40 \pm 0.02$ & $0.26 \pm 0.01$ & $3.7 \pm 0.1$ & $0.48 \pm 0.01$ \\
\hline & 8 & $0.794 \pm 0.006$ & $3.86 \pm 0.02$ & $1.09 \pm 0.03$ & $0.251 \pm 0.008$ & $3.1 \pm 0.1$ & $0.38 \pm 0.02$ \\
\hline & 9 & $0.72 \pm 0.03$ & $3.6 \pm 0.2$ & $0.98 \pm 0.05$ & $0.26 \pm 0.01$ & $2.71 \pm 0.08$ & $0.36 \pm 0.01$ \\
\hline & 10 & $0.67 \pm 0.01$ & $2.83 \pm 0.03$ & $0.94 \pm 0.01$ & $0.265 \pm 0.007$ & $2.34 \pm 0.01$ & $0.33 \pm 0.01$ \\
\hline & 11 & $0.62 \pm 0.02$ & $2.8 \pm 0.1$ & $0.89 \pm 0.03$ & $0.27 \pm 0.01$ & $2.25 \pm 0.009$ & $0.31 \pm 0.01$ \\
\hline & 12 & $0.515 \pm 0.009$ & $2.26 \pm 0.03$ & $0.729 \pm 0.005$ & $0.26 \pm 0.01$ & $1.95 \pm 0.02$ & $0.25 \pm 0.01$ \\
\hline & 13 & $0.49 \pm 0.01$ & $2.08 \pm 0.02$ & $0.69 \pm 0.01$ & $0.27 \pm 0.01$ & $1.93 \pm 0.07$ & $0.239 \pm 0.009$ \\
\hline \multirow{20}{*}{$\begin{array}{l}\text { Filtered cigars } \\
\text { (large and } \\
\text { small) }\end{array}$} & 14 & $0.115 \pm 0.004$ & $0.33 \pm 0.01$ & $0.168 \pm 0.009$ & $0.049 \pm 0.004$ & $0.57 \pm 0.02$ & $0.120 \pm 0.004$ \\
\hline & 15 & $0.088 \pm 0.007$ & $0.32 \pm 0.03$ & $0.120 \pm 0.008$ & BQL & $0.37 \pm 0.02$ & $0.068 \pm 0.003$ \\
\hline & 16 & BQL & $0.26 \pm 0.02$ & $0.128 \pm 0.008$ & $0.044 \pm 0.002$ & $0.52 \pm 0.02$ & $0.09 \pm 0.01$ \\
\hline & 17 & $0.088 \pm 0.005$ & $0.271 \pm 0.004$ & $0.132 \pm 0.005$ & $0.067 \pm 0.003$ & $0.45 \pm 0.04$ & $0.092 \pm 0.002$ \\
\hline & 18 & $0.062 \pm 0.004$ & $0.176 \pm 0.009$ & $0.083 \pm 0.009$ & $0.034 \pm 0.001$ & $0.32 \pm 0.01$ & BQL \\
\hline & 19 & $0.054 \pm 0.001$ & $0.161 \pm 0.002$ & $0.074 \pm 0.002$ & $0.023 \pm 0.001$ & $0.292 \pm 0.008$ & $B Q L$ \\
\hline & 20 & $0.052 \pm 0.004$ & $0.17 \pm 0.01$ & $0.073 \pm 0.006$ & BQL & $0.28 \pm 0.02$ & BQL \\
\hline & 21 & $0.060 \pm 0.006$ & $0.15 \pm 0.02$ & $0.071 \pm 0.006$ & $0.039 \pm 0.001$ & $0.40 \pm 0.03$ & $0.100 \pm 0.009$ \\
\hline & 22 & $0.057 \pm 0.001$ & $0.162 \pm 0.005$ & $0.077 \pm 0.004$ & $0.032 \pm 0.001$ & $0.27 \pm 0.01$ & BQL \\
\hline & 23 & BQL & BQL & $0.069 \pm 0.004$ & BQL & $0.27 \pm 0.02$ & $B Q$ \\
\hline & 24 & BQL & $B Q L$ & $0.067 \pm 0.003$ & BQL & $0.28 \pm 0.01$ & BQL \\
\hline & 25 & $0.052 \pm 0.002$ & $B Q L$ & $0.069 \pm 0.004$ & $0.035 \pm 0.001$ & $0.28 \pm 0.03$ & $B Q L$ \\
\hline & 26 & BQL & $B Q L$ & $0.061 \pm 0.002$ & BQL & $0.29 \pm 0.01$ & $B Q L$ \\
\hline & 27 & $B Q L$ & $B Q$ & $0.062 \pm 0.003$ & $0.026 \pm 0.001$ & $0.20 \pm 0.02$ & BQL \\
\hline & 28 & $0.059 \pm 0.004$ & $B Q$ & $0.070 \pm 0.004$ & $0.035 \pm 0.001$ & $0.43 \pm 0.04$ & $0.11 \pm 0.01$ \\
\hline & 29 & $0.051 \pm 0.004$ & $B Q L$ & $0.070 \pm 0.005$ & $0.027 \pm 0.002$ & $0.21 \pm 0.01$ & BQL \\
\hline & 30 & BQL & $B Q L$ & $0.063 \pm 0.001$ & $0.029 \pm 0.001$ & $0.149 \pm 0.007$ & $B Q L$ \\
\hline & 31 & BQL & $B Q L$ & $0.063 \pm 0.002$ & BQL & $0.183 \pm 0.007$ & $B Q L$ \\
\hline & 32 & BQL & $B Q L$ & $0.059 \pm 0.005$ & BQL & $B Q L$ & $B Q$ \\
\hline & 33 & $B Q$ & $B Q$ & BQL & $B Q$ & $0.18 \pm 0.01$ & BQL \\
\hline \multirow{6}{*}{$\begin{array}{l}\text { Machine rolled } \\
\text { cigars and } \\
\text { cigarillos }\end{array}$} & 34 & $0.071 \pm 0.003$ & $0.22 \pm 0.01$ & $0.115 \pm 0.007$ & $0.029 \pm 0.002$ & $0.25 \pm 0.02$ & $B Q L$ \\
\hline & 35 & $0.076 \pm 0.002$ & $0.214 \pm 0.002$ & $0.093 \pm 0.001$ & $0.032 \pm 0.001$ & $0.382 \pm 0.002$ & $0.077 \pm 0.004$ \\
\hline & 36 & $0.048 \pm 0.002$ & $0.138 \pm 0.007$ & $0.062 \pm 0.001$ & BQL & $0.154 \pm 0.002$ & BQL \\
\hline & 37 & $0.061 \pm 0.004$ & BQL & $0.085 \pm 0.006$ & $B Q L$ & $0.251 \pm 0.009$ & $B Q L$ \\
\hline & 38 & BQL & $B Q$ & $0.055 \pm 0.002$ & $0.030 \pm 0.001$ & $B Q L$ & BQL \\
\hline & 39 & $0.043 \pm 0.003$ & $B Q$ & $0.059 \pm 0.004$ & $0.030 \pm 0.001$ & $B Q L$ & $B Q L$ \\
\hline \multirow{4}{*}{$\begin{array}{l}\text { Machine rolled } \\
\text { pipe tobacco } \\
\text { cigars }\end{array}$} & 40 & $0.172 \pm 0.009$ & $0.57 \pm 0.03$ & $0.230 \pm 0.009$ & $0.129 \pm 0.003$ & $0.182 \pm 0.005$ & $B Q L$ \\
\hline & 41 & $0.150 \pm 0.008$ & $0.40 \pm 0.01$ & $0.198 \pm 0.007$ & $0.117 \pm 0.001$ & $B Q L$ & $B Q$ \\
\hline & 42 & $0.051 \pm 0.002$ & $0.16 \pm 0.01$ & $0.061 \pm 0.001$ & BQL & $B Q$ & $B Q L$ \\
\hline & 43 & BQL & BQL & BQL & $B Q L$ & $B Q L$ & $B Q L$ \\
\hline
\end{tabular}

limiting ME in the detector. They also limited the dynamic range of the analysis and meant that analytes in many samples were below the quantitation limit of the method. As was observed during validation, the potential for ME to affect the performance of the method is evident and significantly expanding its applicability would likely require sample cleanup steps to mitigate $\mathrm{ME}$ while concentrating analytes in the matrix. A less radical modification that would allow for quantitation of polyphenol analytes in a larger number of cigar samples would be to limit the application of the method to American blended cigarettes (ABC) and cigars and modify the linear ranges of the calibration curves to expand the low end of the range. Even with these potential modifications, since air-curing and fermentation inevitably consume polyphenols, it is unreasonable to expect that all samples will contain quantifiable levels of these analytes.

Trends in the polyphenol content of flue- and air-cured tobacco leaves reflect current understanding of the effect of each curing regimen on the metabolic processes that occur as the leaf dries. There may be some interest found in the polyphenol content of the Oriental tobaccos, which overlapped the results for flue-cured leaves. Given that enzyme deactivation is associated with the fate of polyphenols during flue-curing, perhaps the results observed for Oriental tobaccos might be explained by photochemical inactivation of the enzymes responsible for phenolic oxidation. When considering the polyphenol content of 

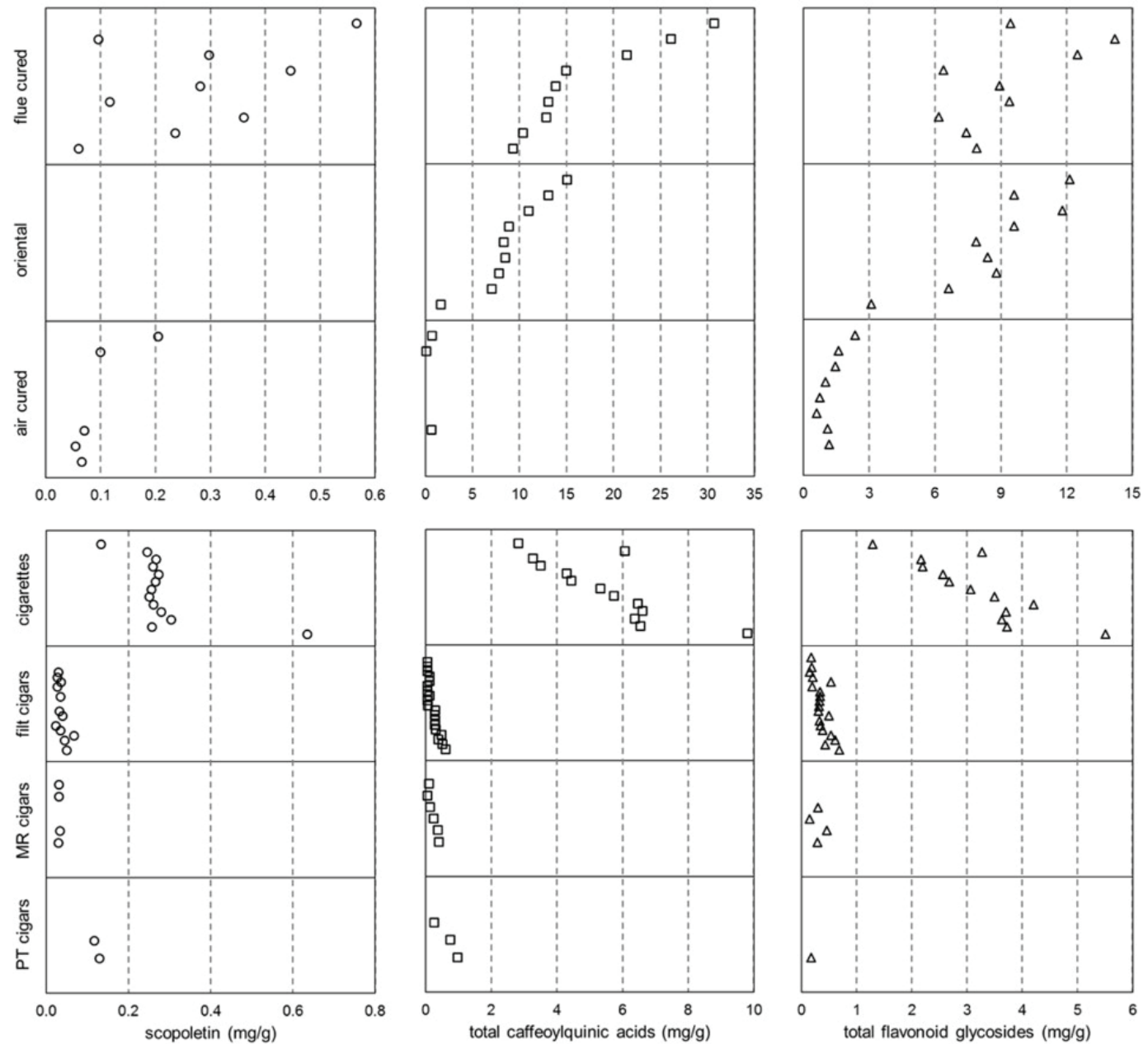

Figure 3. Results of analysis for 6 polyphenols found in 27 samples of flue-cured, air cured, and oriental tobacco leaves (top) and 43 samples of cigarettes, filtered and machine rolled large cigars, and pipe tobacco cigars (bottom). Polyphenols grouped under total caffeoylquinic acids (3-CQA, 4-CQA, and 5-CQA) and total flavonoid glycosides (rutin and nicotiflorin). Scopoletin was the only coumarin studied in tobacco leaves and tobacco products.

cigars and cigarettes, it is reasonable to conclude that there is a relationship between the type(s) of cured tobacco traditionally used in each type of product and the results of the analyses presented here. Almost all cigarettes studied here were of the ABC type. Along with components such as reconstituted sheet tobacco, expanded stem and lamina, and air-cured tobacco, these products can contain up to $35 \%$ flue-cured tobacco (33) and would explain, at least in part, the higher polyphenol content relative to the other product categories. Standing in contrast, due to the traditionally heavy use of air-cured tobaccos in the production of cigar products, it is reasonable to anticipate the consistently low polyphenol content observed across the limited range of products analyzed here. It should be noted that degradation of polyphenols resulting from exposure to commonly used additives such as ammonia is possible and have been reported in the literature (34). However, this reaction will require more studies to understand its impact on polyphenol content in finished tobacco products.

It is important to point out that samples were identified as cigars, cigarettes, and pipe tobacco based solely on the packaging provided by the manufacturer and any comparison where product type was involved were based on the product label. Additionally, product identities were omitted from this paper because the results of this analysis were not intended to be used to draw conclusions about specific products.

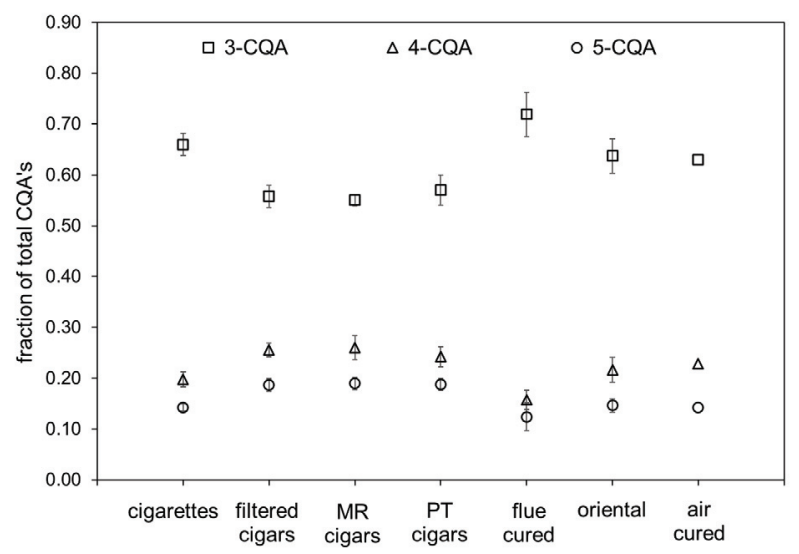

Figure 4. Graph of relative ratios of 3-, 4-, and 5-CQA in whole leaf tobacco and tobacco products. Ratios calculated versus total caffeoylquinic acid content. The error bars represent the standard deviation across each group of products or leaf type. 
As was indicated above, data analysis was focused entirely on trends observed across product types and curing processes. Any comparisons made between the results listed in the tables and figures was done to highlight trends and demonstrate that this method can be used to study polyphenol content in tobacco products and leaf material.

\section{ACKNOWLEDGEMENTS}

The authors would like to thank Dr. Abdul Mabud of the Alcohol \& Tobacco Tax \& Trade Bureau and Rachael Schmidt of the U.S. Food and Drug Administration - Center for Tobacco Products for their support of this research project.

\section{REFERENCES}

1. Sheen, S.J. and J. Calvert: Studies on Polyphenol Content, Activities and Isozymes of Polyphenol Oxidase and Peroxidase During Air-Curing in Three Tobacco Types; Plant Physiol. 44 (1969) 199-204.

DOI: $10.1104 / p p .44 .2 .199$

2. Wright, Jr, H.E.: The Phenolics of Tobacco and Their Significance; Symposium at the Plant Phenolics of North America, Oregon State University, Corvallis, OR, USA, $24^{\text {th }}$ August, 1962.

3. Kallianos, A.G.: Phenolics and Acids in Leaf and Their Relationship to Smoking Quality and Aroma; Rec. Adv. Tob. Sci. 20 (1976) 61-79.

4. Snook, M.E. and O.T. Chortyk: An Improved Extraction-HPLC Method for Tobacco Polyphenols; Tob. Sci. 26 (1993) 25-29. DOI: 10.1104/pp.106.078428

5. Moco, S., R.J. Bino, O. Vorst, H.A. Verhoeven, J. de Groot, T.A. van Beek, J. Vervoort, and C.H. Ric de Vos: A Liquid Chromatography-Mass Spectrometry-Based Metabolome Database for Tomato; Plant Physiol. 141 (2006) 1205-1218.

6. Wright, H.E., W.W. Burton, and R.C. Berry, Jr: Soluble Browning Reaction Pigments of Aged Burley TobaccoII. The Dialysable Fraction; Phytochemistry 3 (1964) 525-533. DOI: 10.1016/S0031-9422(00)88030-9

7. Li, Z., L. Wang, G. Yang, H. Shi, C. Jiang, W. Liu, and Y. Zhang: Study on the Determination of Polyphenols in Tobacco by HPLC Coupled With ESI-MS After SolidPhase Extraction; J. Chromatogr. Sci. 41 (2003) 36-40. DOI: $10.1093 /$ chromsci/41.1.36

8. Gu, X., J. Cai, X. Zhu, and Q. Su: Dynamic UltrasoundAssisted Extraction of Polyphenols in Tobacco; J. Sep. Sci. 28 (2005) 2435-2561.

DOI: $10.1002 /$ jssc. 200500064

9. Dagnon, S. and A. Edreva: Application of Pattern Recognition Method for Color Assessment of Oriental Tobacco Based on HPLC of Polyphenols; Beitr. Tabakforsch. Int. 20 (2003) 355-359.

DOI: $10.2478 /$ cttr-2013-0750

10. Aramendía, M.A., I.M. García, F. Lafont, J. Lizaso, J.M. Marinas, and F.J. Urbano: Rapid Determination of Chlorogenic Acid and Related Compounds in Sunflower Seeds by High-Performance Liquid Chromatography/ Atmospheric Pressure Chemical Ionization Mass Spectrometry; Rapid Commun. Mass Spectrom. 14 (2000) 1019-1022.

DOI: $10.1002 / 1097-0231(20000630) 14: 12<1019:: A I$
D-RCM981>3.0.CO;2-9

11. Clifford, M.N., K.L. Johnston, S. Knight, and N. Kuhnert: Hierarchical Scheme for LC-MS ${ }^{\mathrm{n}}$ Identification of Chlorogenic Acids; J. Agr. Food Chem. 51 (2003) 2900-2911. DOI: 10.1021/jf026187q

12. Zhao, R., F. Li, and J. Hu: Rapid Determination of Polyphenols in cut Tobacco by Microwave-Assisted Extraction-Ultrahigh Performance Liquid Chromatography; Anal. Methods 3 (2011) 2421-2424.

13. Xiang, G., L. Yang, X. Zhang, H. Yang, Z. Ren, and M. Miao: A Comparison of Three Methods of Extraction for the Determination of Polyphenols and Organic Acids in Tobacco by UPLC-MS-MS; Chromatographia 70 (2009) 1007-1010. DOI: 10.1365/s10337-009-1253-2

14. Dawidowicz, A.L, D. Wianowska, J. Gawdzik, and D.H. Smolarz: Optimization of ASE Conditions for the HPLC Determination of Rutin and Isoquercitrin in Sambucus nigra L; J. Liq. Chromatogr. Relat. Technol. 26 (2003) 2381-2397. DOI:10.1081/JLC-120023253

15. Xie, F., A. Yu, D. Hou, H. Liu, L. Ding, and S. Zhang: Rapid and Sensitive Analysis of Eight Polyphenols in Tobacco by Rapid Resolution Liquid Chromatography; Am. J. Anal. Chem. 2 (2011) 929-933.

DOI: 10.4236/ajac.2011.28107

16. Li, Z., L. Wang, G. Yang, H. Shi, C. Jiang, W. Liu, and Y. Zhang: Study on the Determination of Polyphenols in Tobacco by HPLC Coupled with ESI-MS After SolidPhase Extraction; J. Chromatogr. Sci. 41 (2003) 36-40. DOI: $10.1093 /$ chromsci/41.1.36

17. Papagiannopoulos, M. and A. Mellenthin: Accelerated Solvent Extraction in the Investigation of Polyphenols in the Brewing Process; Special Publication - Royal Society of Chemistry (2001), 269 (Biologically-Active Phytochemicals in Food), 199-201.

18. Ezzell, J.: Investigations of Thermal Degradation During Accelerated Solvent Extraction (ASE); Dionex Technical Note 206, Thermo Fisher Scientific, Sunnyvale, CA, USA, 2001. Available at: https:/www. thermofisher.com/content/dam/tfs/ATG/CMD/CMD $\%$ 20Documents/Application\%20\&\%20Technical\%20 Notes/TN-206-Investigations-Thermal-DegradationTN71096-EN.pdf

19. Li, X.Q., X.H. Sun, S. Cai, X.X. Ying, and F.M. Li: Investigation on the Chemical Constituents and Variation of the Flower Buds of Lonicera Species by UPLC-ESI-MS/MS and Principle Component Analysis; Acta Pharmaceutica Sinica 44 (2009) 895-904.

20. Ruiz, A., C. Mardones, C. Vergara, I. HermosinGutierrez, D. von Baer, P. Hinrichsen, R. Rodriguez, D. Arribillaga, and E. Dominguez: Analysis of Hydroxycinnamic Acids Derivatives in Calafate (Berberis microphylla G. Forst) Berries by Liquid Chromatography with Photodiode Array and Mass Spectrometry Detection; J. Chromatogr. A 1281 (2013) 38-45. DOI: 10.1016/j.chroma.2013.01.059

21. Torras-Claveria, L., O. Jáuregui, C. Codina, A. Tiburcio, J. Bastida, and F. Viladomat: Analysis of Phenolic Compounds by High-Performance Liquid Chromatography Coupled to Electrospray Ionization Tandem Mass Spectrometry in Senescent and Water-Stressed Tobacco; Plant Sci. 182 (2012) 71-78. DOI: 10.1016/j.plantsci.2011.02.009

22. Fang, N., S. Yu, and R.L. Prior: LC/MS/MS Characterization of Phenolic Constituents in Dried Plums; J. Agr. Food Chem. 50 (2002) 3579-3585. 
DOI: $10.1021 / \mathrm{jf0} 201327$

23. Hvattum, E. and D. Ekeberg: Study of the CollisionInduced Radical Cleavage of Flavonoid Glycosides Using Negative Electrospray Ionization Tandem Quadrupole Mass Spectrometry; J. Mass Spectrom. 38(2003) 43-49. DOI: 10.1002/jms.398

24. Sánchez-Rabaneda, F., O. Jáuregui, I. Casals, C. AndrésLacueva, M. Izquierdo-Pulido, and R.M. LamuelaRaventós: Liquid Chromatographic/Electrospray Ionization Tandem Mass Spectrometric Study of the Phenolic Composition of Cocoa (Theobroma cacao); J. Mass Spectrom. 38 (2003) 35-42. DOI: 10.1002/jms.395

25. Dawa, Z., Y. Zhou, Y. Bai, S. Gesang, J. Liang, and L. Ding: Analysis of Saussurea Species from Tibet Using HPLC-DAD-ESI-MSn; Acta Chromatogr. 22 (2010) 141-152. DOI: 10.1556/AChrom.22.2010.1.11

26. Xiang, G., H. Yang, L. Yang, X. Zhang, Q. Cao, and M. Miao: Multivariate Statistical Analysis of Tobacco of Different Origin, Grade and Variety According to Polyphenols and Organic Acids; Microchem. J. 95 (2010) 198-206. DOI: 10.1016/j.microc.2009.12.001

27. International Conference On Harmonisation Of Technical Requirements for Registration of Pharmaceuticals for Human Use (ICH): ICH Harmonized Tripartite Guideline. Validation of Analytical Procedures: Text and Methodology Q2(R1), 2005. Available at: https://www.ich.org/fileadmin/Public_Web_Site/ICH _Products/Guidelines/Quality/Q2_R1/Step4/Q2_R1 Guideline.pdf (accessed November 2017).

28. Dolan, J.W.: LC Troubleshooting - Calibration Curves, Part II: What are the Limits?; LCGC North America 27 (2009) 306-312. Available at: http://www.chromato graphyonline.com/calibration-curves-part-ii-what-arelimits (accessed December 2017)

29. Nguyen, H.P., L. Li, I.S. Nethrapalli, N. Guo, C.D. Toran-Allerand, D.E. Harrison, C.M. Astle, and K.A. Schug: Evaluation of Matrix Effects in Analysis of Estrogen Using Liquid Chromatography-Tandem Mass Spectrometry; J. Sep. Sci. 34 (2011) 1781-1787. DOI: $10.1002 /$ jssc.201100219
30. National Association of Testing Authorities, Australia (NATA): Guidelines for the Validation and Verification of Quantitative and Qualitative Test Methods, Technical Note 17; 2013. Available at: https://www.nata.com. $\mathrm{au} /$ nata/accreditation-publication/nata-accreditation-g uidance-and-information/category/50-nata-tech-notesinfo-papers (accessed December 2017)

31. Matuszewski, B.K., M.L. Constanzer, and C.M. ChavezEng: Strategies for the Assessment of Matrix Effect in Quantitative Bioanalytical Methods Based on HPLCMS/MS; Anal. Chem. 75 (2003) 3019-3030. DOI: $10.1021 / \mathrm{ac} 020361 \mathrm{~s}$

32. Shaw, P.N., S.K. Tan, and A. Hewavitharana: Strategies for the Detection and Elimination of Matrix Effects in Quantitative LC-MS Analysis; LCGC North America 32 (2014) 54-64. Available at: http://www.chromato graphyonline.com/strategies-detection-and-eliminatio n-matrix-effects-quantitative-lc-ms-analysis (accessed December 2017)

33. Abdallah, F.: What Makes Tobacco? Flavor Characteristics of Tobacco Smoke; Tob. Reporter, December (2002) 54-57. ISSN.0361-5693

34. Salunkhe, D.K., S.J Jadhav, S.S. Kadam, and J.K. Chavan: Chemical, Biochemical, and Biological Significance of Polyphenols in Cereals and Legumes; Crit. Rev. Food Sci. Nutr. 17 (1982) 277-305.

DOI: $10.1080 / 10408398209527350$

\section{Corresponding Author:}

John R. Shifflett, M.S.

United States Department of the Treasury

Alcohol and Tobacco Tax and Trade Bureau (TTB)

Scientific Services Division

6000 Ammendale Road

Beltsville, MD 20705, USA

E-mail:John.Shifflett@ttb.gov 